\title{
Ascertainment of Individual Risk of Mortality for Patients with Idiopathic Pulmonary Fibrosis
}

\author{
Roland M. du Bois ${ }^{1}$, Derek Weycker ${ }^{2}$, Carlo Albera ${ }^{3}$, Williamson Z. Bradford 4 , Ulrich Costabel ${ }^{5}$, \\ Alex Kartashov, Lisa Lancaster6, Paul W. Noble7, Ganesh Raghu8, Steven A. Sahn ${ }^{9}$, \\ Javier Szwarcberg, ${ }^{4}$ Michiel Thomeer ${ }^{10}$, Dominique Valeyre ${ }^{11}$, and Talmadge E. King, Jr. ${ }^{12}$
}

\begin{abstract}
${ }^{1}$ Imperial College, London, United Kingdom; ${ }^{2}$ Policy Analysis Inc., Brookline, Massachusetts; ${ }^{3}$ Department of Clinical and Biological Sciences, University of Turin, Turin, Italy; ${ }^{4}$ InterMune Inc., Brisbane, California; ${ }^{5}$ Ruhrlandklinik and Medical Faculty, University of Duisburg/Essen, Essen, Germany; ${ }^{6}$ Vanderbilt University Medical Center, Nashville, Tennessee; ${ }^{7}$ Duke University School of Medicine, Durham, North Carolina; ${ }^{8}$ University of Washington School of Medicine, Seattle, Washington; ${ }^{9}$ Medical University of South Carolina, Charleston, South Carolina; ${ }^{10}$ University Hospital Gasthuisberg, Leuven, Belgium; ${ }^{11}$ Assistance Publique-Hôpitaux de Paris, Hospital Avicenne, Bobigny, France; and ${ }^{12}$ University of California, San Francisco, California
\end{abstract}

Rationale: Several predictors of mortality in patients with idiopathic pulmonary fibrosis have been described; however, there is a need for a practical and accurate method of quantifying the prognosis of individual patients.

Objectives: Develop a practical mortality risk scoring system for patients with idiopathic pulmonary fibrosis.

Methods: We used a Cox proportional hazards model and data from two clinical trials $(n=1,099)$ to identify independent predictors of 1-year mortality among patients with idiopathic pulmonary fibrosis. From the comprehensive model, an abbreviated clinical model comprised of only those predictors that are readily and reliably ascertained by clinicians was derived. Beta coefficients for each predictor were then used to develop a practical mortality risk scoring system. Measurements and Main Results: Independent predictors of mortality included age, respiratory hospitalization, percent predicted FVC, 24week change in FVC, percent predicted carbon monoxide diffusing capacity, 24-week change in percent predicted carbon monoxide diffusing capacity, and 24-week change in health-related quality of life. An abbreviated clinical model comprising only four predictors (age, respiratory hospitalization, percent predicted FVC, and 24-wk change in FVC), and the corresponding risk scoring system produced estimates of 1-year mortality risk consistent with observed data $(9.9 \%$ vs. $9.7 \%$; $C$ statistic $=0.75 ; 95 \%$ confidence interval, 0.71-0.79).

Conclusions: The prognosis for patients with idiopathic pulmonary fibrosis may be accurately determined using four readily ascertainable predictors. Our simplified scoring system may be a valuable tool for determining prognosis and guiding clinical management. Additional research is needed to validate the applicability and accuracy of the scoring system.

Keywords: interstitial lung disease; risk factors; vital capacity; mortality Idiopathic pulmonary fibrosis (IPF) is a progressive, lifethreatening, interstitial lung disease of unknown etiology (1).

(Received in original form November 4, 2010; accepted in final form May 5, 2011) Supported by InterMune Inc., Brisbane, CA.

Contributors: R.M.d B., C.A., W.Z.B., U.C., L.L., P.W.N., G.R., I.S., S.A.S., M.T., D.V., and T.E.K., Jr. participated in the design, conduct, analysis, and reporting of study protocol GIPF-007. G.R., P.W.N., T.E.K., Jr., and W.Z.B. participated in the design, conduct, analysis, and reporting of study protocol GIPF-001. R.M.d B., W.Z.B., D.W., and A.K. participated in the design, analysis, and reporting of the present study. C.A., U.C., L.L., P.W.N., G.R., J.S., S.A.S., M.T., D.V., and T.E.K., Jr. participated in the analysis and reporting of the present study.

Correspondence and requests for reprints should be addressed to Roland $\mathrm{M}$. du Bois, M.D., Imperial College, 1B Manresa Road, London SW3 6LR, UK. E-mail: ron@du-bois.co.uk

This article has an online supplement, which is accessible from this issue's table of contents at www.atsjournals.org

Am J Respir Crit Care Med Vol 184. pp 459-466, 2011

Originally Published in Press as DOI: 10.1164/rccm.201011-17900C on May 26, 2011 Internet address: www.atsjournals.org

\section{AT A GLANCE COMMENTARY}

\section{Scientific Knowledge on the Subject}

Several studies have identified independent predictors of mortality in patients with idiopathic pulmonary fibrosis. Research published to date, however, has failed to yield a scoring system to predict individual risk of mortality.

\section{What This Study Adds to the Field}

Our findings suggest that a practical risk scoring system based on four readily and reliably ascertainable predictors may be used to accurately assess the risk of 1-year mortality in individual patients with idiopathic pulmonary fibrosis and thereby facilitate clinical decision making. Validation of the risk scoring system in other populations of patients with idiopathic pulmonary fibrosis is needed.

Respiratory failure resulting from IPF is the most frequent cause of death, and has been reported to account for over $80 \%$ of all fatalities $(2,3)$. Heart failure, bronchogenic carcinoma, ischemic heart disease, infection, and pulmonary embolism are also causes of mortality in IPF (3).

Although median survival among patients with IPF is only 2 to 3 years, some patients live much longer. Several studies have focused on identifying predictors of mortality in patients with IPF, including those based on data obtained at a single point in time (baseline predictors), and those based on data obtained over time (longitudinal predictors) (1, 4-18). Research published to date, however, has been limited in one or more facets of study design or study population, including retrospective data collection, small sample size, or use of a putative predictor that is not commonly assessed in clinical practice. Moreover, presumably because of these limitations, research in this area has failed to yield a scoring system that is routinely used in clinical practice to predict individual risk of mortality $(4,5)$. Development of such a scoring system is important, because it may serve as a basis for clinical decision making and simplify clinical trial design.

Using data from two large clinical trials in patients with IPF, we undertook a study to identify independent predictors of mortality and, based on these findings, develop a risk scoring system that once validated could be used by clinicians in daily practice without the need for sophisticated measures of disease status that are available only in specialized centers. This work has been presented in part at the 2010 international meeting of the American Thoracic Society (19). 


\section{METHODS}

\section{Source and Study Populations}

The source population consisted of all randomized patients $(n=1,156)$ in two clinical trials of IFN- $\gamma 1 \mathrm{~b}$ (protocols GIPF-001 [n = 330] and GIPF$007[n=826]$ ) irrespective of treatment assignment (placebo $[n=443]$ or IFN- $\gamma 1 \mathrm{~b}[\mathrm{n}=713])$. The designs of these trials are described in detail elsewhere $(2,20)$. Briefly, eligible patients were required to have a highresolution computed tomography scan showing features consistent with protocol-defined criteria for either a definite or probable diagnosis of IPF. Surgical lung biopsy was required to confirm a diagnosis in all patients with a clinical and radiographic diagnosis of probable IPF, and all patients under the age of 50 years, regardless of the degree of certainty associated with the clinical and radiographic diagnoses.

From the source population, we selected for inclusion all patients $(\mathrm{n}=1,099)$ who participated in the week-24 trial visit (data from the week-24 visit were required to characterize changes from baseline in longitudinal predictors) (Figure 1). Patients who died or had a lung transplant between baseline and the week-24 visit $(n=39)$, or who were lost to follow-up during this period $(\mathrm{n}=18)$, were therefore excluded from the analyses.

\section{Predictors of Mortality}

Potential predictors of mortality were assessed during the period from the trial baseline to the week-24 trial visit, and during the period from the week-48 to the week-72 trial visits, respectively, and all deaths occurring over the 48 -week periods after these periods were identified. Specifically, a record was created for each patient consisting of data on predictors from the baseline and week-24 visits and, if observed, the week-48 and week-72 trial visits, respectively, and patients who died during the subsequent 48 weeks were flagged accordingly. All such records were pooled into a single dataset for analysis; therefore, patients may have contributed up to two unique observations to the study database.

Potential predictors were identified a priori based on biologic plausibility and clinical rationale. Patient sex, race, smoking status, history of cardiovascular disease, presence of honeycombing on highresolution computed tomography scans, use of supplemental oxygen, and history of surgical lung biopsy were evaluated based on information collected at the baseline visit. Age, body mass index, use of concomitant medications, percent predicted FVC, percent predicted carbon monoxide diffusing capacity ( $\left.\mathrm{DL}_{\mathrm{CO}}\right)$, the University of California at San Diego Shortness of Breath Questionnaire (UCSD SOBQ), and the St. George's Respiratory Questionnaire (SGRQ) were evaluated at the baseline and week-48 trial visits (for baseline data corresponding to the week-24 and week-72 trial visits, respectively). Longitudinal changes in measures of physiologic status, dyspnea (assessed by the UCSD SOBQ), and health-related quality of life
(HRQL, assessed by the SGRQ), and the occurrence of respiratory hospitalization, were evaluated over the 24 -week periods immediately preceding the week-24 and week-72 trial visits. Trial treatment assignment (IFN- $\gamma 1$ b vs. placebo), trial enrollment (GIPF-001 vs. GIPF-007), and country of residence were included as possible confounders.

\section{Statistical Analyses}

Crude (unadjusted) risks of all-cause mortality (per person-year) were estimated for patients stratified by each potential predictor separately, as were corresponding (unadjusted) hazard ratios using Cox proportional hazards models. To optimize model fit and aid in interpretation of study results, potential predictors that are continuous in nature were characterized using categorical variables, because such variables exhibited in formal and informal tests a nonlinear relationship with mortality. Thresholds separating categories for a given predictor were defined initially based on the quintiles of their distributions; some thresholds were subsequently modified based on distributional properties of the empirical data and thresholds previously used in published clinical research (see Table E1 in the online supplement).

A multivariate Cox proportional hazards model was estimated to identify independent predictors of all-cause mortality. All dichotomous measures with $P$ values less than 0.10 in unadjusted analyses were initially included in the model; grouped dichotomous variables were included if any of the grouped variables had a $P$ value less than 0.10 . We subsequently excluded from this model all variables that were no longer important predictors in a multivariate context. The robustness of the final specification to alternative approaches for eliminating variables from the model was evaluated.

From the fully specified model, an abbreviated clinical model comprised only of predictors that are readily and reliably evaluable by clinicians and that might be used to assess patient risk in clinical practice was also estimated. The importance of interactions between all levels of selected predictors, along with the selected predictors, was evaluated by the stepAIC method using backward and forward selection.

Only observed data were used (i.e., missing values were not imputed); therefore, the size of the study population may be slightly different across analyses, as noted. Subjects who underwent lung transplant $(\mathrm{n}=28)$ during follow-up were censored on the corresponding date. The presence of multicollinearity, hazards assumptions, and model discrimination were evaluated using published methods $(21,22)$. Model discrimination was quantified based on the $\mathrm{C}$ statistic, which is the probability that among two randomly selected patients the patient with the higher predicted risk of an event will be the first to experience the event. The $\mathrm{C}$ statistic ranges from 0.5 (model discrimination is no better than chance) to 1 (model discrimination is perfect). A C statistic between 0.70 and 0.80 is typically considered "acceptable," whereas a value exceeding 0.80 is typically considered "excellent."

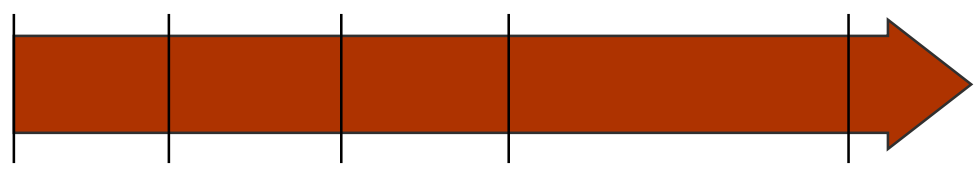

$\begin{array}{lllll}\text { Original Baseline Wk } 24 & \text { Wk } 48 & \text { Wk } 72 & \text { Wk } 120\end{array}$

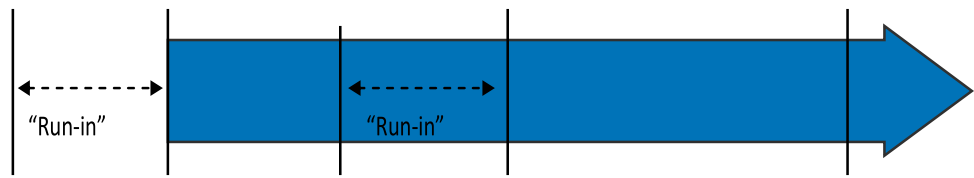

Figure 1. Schematic of study design. 
A mortality risk scoring system was developed using methodology set forth by Wilson and coworkers (23) and used in other studies (24, $25)$. Specifically, $\beta$ coefficients from the abbreviated Cox model were converted to scores by multiplying each by 10 and rounding to the nearest integer. A mortality risk score was calculated for each study subject by summing the individual scores corresponding to his or her characteristics; the baseline hazard function from the Cox model was then used to convert the total risk score to a 1-year probability of death

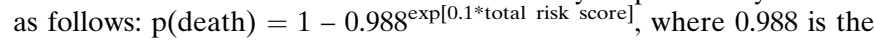
estimated 1-year probability of survival, and thus $1-0.988$ is the estimated 1-year probability of death for persons with the lowest risk (i.e., those with a total risk score equal to 0 ). To verify that estimates of risk produced by the scoring system were consistent with observed data, subjects were stratified into quintiles based on their risk scores, and average risks calculated from the scoring system were compared with observed risks (using the Kaplan-Meier method). Calibration and discrimination were evaluated using the chi-square statistic and $\mathrm{C}$ statistic, respectively.

\section{RESULTS}

\section{Patient Characteristics}

Among the 1,156 patients with IPF who were enrolled in the two clinical trials of IFN- $\gamma 1$ b, 1,099 participated in the week-24 trial visit and thus qualified for inclusion in the study population (Table 1). Mean age was $65(\mathrm{SD}=8)$ years, $70 \%$ were male, and $75 \%$ were United States residents. Mean baseline percent predicted FVC was $68(\mathrm{SD}=14)$, and percent predicted $\mathrm{DL}_{\mathrm{CO}}$ was $42(\mathrm{SD}=12)$. Among the 1,099 patients, 830 participated in the week-72 visit; thus, the study database included a total of 1,929 patient-visits.

\section{Predictors of Mortality}

There were a total of 152 deaths; 98 deaths occurred between the week-24 and week-72 trial visits (mean duration of follow-up, $43 \mathrm{wk})$, whereas the remainder $(\mathrm{n}=54)$ occurred during the 48-week period after the week-72 trial visit (mean duration of follow-up, $29 \mathrm{wk}$ ). Crude 1-year risk of mortality was $9.7 \%$ (95\% confidence interval [CI], 8.2-11.2). Unadjusted risks of mortality were systematically different $(P<0.10)$ across one or more strata for the following variables: age; supplemental

\section{TABLE 1. BASELINE CHARACTERISTICS OF PATIENTS WITH} IDIOPATHIC PULMONARY FIBROSIS

\begin{tabular}{lc}
\hline Characteristics & $\mathrm{N}(\%)$ \\
\hline Demographic & \\
Age, yr & \\
$\quad<60$ & $240(21.8)$ \\
$60-69$ & $473(43.1)$ \\
$\geqslant 70$ & $386(35.1)$ \\
Male & $772(70.2)$ \\
Race & \\
White & $1,013(92.2)$ \\
Other & $86(7.8)$ \\
Country of residence & \\
$\quad$ United States & $826(75.2)$ \\
Other & $273(24.8)$ \\
Clinical & \\
Honeycombing on HRCT & $947(86.2)$ \\
Surgical lung biopsy & $638(58.1)$ \\
History of cardiovascular disease & $299(27.2)$ \\
Treatment assignment & \\
Placebo & \\
IFN- $\gamma 1 b$ & $418(38)$ \\
Study & $681(62)$ \\
$\quad$ GIPF-007 & \\
GIPF-001 & $801(72.9)$ \\
\hline Definition & $298(27.1)$ \\
\hline
\end{tabular}

Definition of abbreviation: HRCT = high-resolution computed tomography. oxygen use; history of surgical lung biopsy; 24-week history of respiratory hospitalization; prednisone use; azathioprine use; percent predicted FVC; 24-week change in percent predicted FVC; percent predicted $\mathrm{DL}_{\mathrm{CO}} ; 24$-week change in percent predicted $\mathrm{DL}_{\mathrm{CO}}$; dyspnea score (assessed by UCSD SOBQ); 24-week change in dyspnea score; HRQL (assessed by SGRQ); and 24-week change in HRQL (Table 2).

In the multivariate model, statistically significant independent predictors of all-cause mortality included age, history of respiratory hospitalization, percent predicted FVC, 24-week change in percent predicted FVC, percent predicted DL ${ }_{\mathrm{CO}}, 24$-week change in percent predicted DL $\mathrm{CO}$, and 24-week change in HRQL (Table 3). This comprehensive model was found to be robust across alternative approaches for eliminating variables from the model, with each yielding the same set of predictors. Model discrimination, based on the C statistic, was 0.77 (95\% CI, 0.72-0.81).

From the comprehensive model, an abbreviated clinical model including only those factors that are readily and reliably evaluable in the typical clinical setting was derived. These included age, 24-week history of respiratory hospitalization, percent predicted FVC, and 24-week change in percent predicted FVC (Table 3). Among these, the strongest independent predictor of mortality was the 24-week change in percent predicted FVC. Of note, a $24-$ week change of $-5 \%$ to $-9.9 \%$ was associated with a more than twofold increase in the risk of death over the subsequent 12 months (hazard ratio [HR], 2.60 [95\% CI, 1.75-3.85; $P<0.001]$ ), whereas a decline greater than or equal to $10 \%$ was associated with an eightfold increase in the risk of 1-year mortality (HR, 7.99 [95\% CI, 5.26-12.14; $P<$ $0.001]$ ). Model discrimination for the clinical model was 0.75 (95\% CI, 0.71-0.79), indicating that the discriminatory power was comparable with that of the comprehensive model. Multicollinearity between independent variables and nonproportional hazards were determined not to be significant in any of the multivariate models, and results were robust across models when focusing on the subset of patient visits $(n=1,444)$ with data available for all potential predictors. Consideration of interaction terms in the clinical model selected by the stepAIC method failed to improve model discrimination.

\section{Mortality Risk Scoring System}

A simplified mortality risk scoring system was developed based on the $\beta$ coefficients for each predictor in the abbreviated Cox model. The mortality risk scoring system is presented in Table 4. Overall, the scoring system overestimated mortality risk by, in relative terms, less than $2 \%$ (observed risk, $9.7 \%$ vs. estimated risk from scoring system, 9.9\%) (Table 5). The ratio of risk from the scoring system to observed risk ranged from 0.65-1.13 across patient quintiles; absolute differences ranged from $0.3-2 \%$. Calibration $(P$ value $=0.316)$ and discrimination $(\mathrm{C}$ statistic $=0.75[95 \% \mathrm{CI}, 0.71-0.80])$ of the scoring system were good.

The expected 1-year risk of mortality for an individual patient can be ascertained by summing the scores for each of the four predictors and comparing the total score with the corresponding expected 1-year risk of mortality (Table 4). For example, the total score for a 66-year-old patient with a history of respiratory hospitalization, a percent predicted FVC of $68 \%$, and a 24 -week change in percent predicted FVC of less than $-5 \%$ is $26(4+14$ $+8+0)$, which corresponds to a $10-20 \%$ risk of 1 -year mortality. By contrast, the total score for a patient with the same age, baseline FVC, and history of respiratory hospitalization, yet with a 24-week change in percent predicted FVC between -5 and $-9.9 \%$, is $36(4+14+8+10)$, which corresponds to a $30-40 \%$ risk of $1-y e a r$ mortality. 
TABLE 2. UNADJUSTED ANALYSES OF PREDICTORS OF ALL-CAUSE MORTALITY AMONG PATIENTS WITH IDIOPATHIC PULMONARY FIBROSIS

\begin{tabular}{|c|c|c|c|c|c|c|}
\hline Covariates & Subject Visits $(n)$ & Deaths $(n)$ & Deaths (\%) & $\mathrm{HR}$ & $95 \% \mathrm{Cl}$ & $P$ Value \\
\hline \multicolumn{7}{|l|}{ Demographic } \\
\hline \multicolumn{7}{|l|}{ Age } \\
\hline$<60$ & 417 & 22 & 5.3 & 0.51 & $0.32-0.83$ & 0.006 \\
\hline $60-69$ & 817 & 59 & 7.2 & 0.71 & $0.50-1.00$ & 0.053 \\
\hline$\geqslant 70$ & 690 & 71 & 10.3 & - & - & - \\
\hline \multicolumn{7}{|l|}{ Sex } \\
\hline Male & 1,347 & 113 & 8.4 & 1.23 & $0.86-1.77$ & 0.262 \\
\hline Female & 577 & 39 & 6.8 & - & - & - \\
\hline \multicolumn{7}{|l|}{ Race } \\
\hline White & 1,775 & 139 & 7.8 & 0.95 & $0.54-1.69$ & 0.865 \\
\hline Other & 149 & 13 & 8.7 & - & - & - \\
\hline \multicolumn{7}{|l|}{ Country } \\
\hline United States & 1,459 & 109 & 7.5 & 0.79 & $0.56-1.13$ & 0.202 \\
\hline Other & 465 & 43 & 9.2 & - & - & - \\
\hline \multicolumn{7}{|l|}{ Clinical } \\
\hline \multicolumn{7}{|l|}{ Current smoker } \\
\hline Yes & 92 & 4 & 4.3 & 0.49 & $0.18-1.32$ & 0.157 \\
\hline No & 1,832 & 148 & 8.1 & - & - & - \\
\hline \multicolumn{7}{|l|}{ Oxygen use } \\
\hline Yes & 485 & 58 & 12 & 1.85 & $1.34-2.57$ & $<0.001$ \\
\hline No & 1,431 & 94 & 6.6 & - & - & - \\
\hline \multicolumn{7}{|c|}{ Honeycombing on HRCT } \\
\hline Yes & 1,652 & 132 & 8 & 1.07 & $0.67-1.71$ & 0.790 \\
\hline No & 271 & 20 & 7.4 & - & - & - \\
\hline \multicolumn{7}{|l|}{ Surgical lung biopsy } \\
\hline Yes & 1,126 & 72 & 6.4 & 0.62 & $0.45-0.86$ & 0.004 \\
\hline No & 795 & 80 & 10.1 & - & - & - \\
\hline \multicolumn{7}{|c|}{ History of cardiovascular disease } \\
\hline Yes & 520 & 41 & 7.9 & 1.00 & $0.70-1.43$ & 0.991 \\
\hline No & 1,404 & 111 & 7.9 & - & - & - \\
\hline History of respiratory & italization & & & & & \\
\hline Yes & 77 & 26 & 33.8 & 6.22 & $4.07-9.49$ & $<0.001$ \\
\hline No & 1,847 & 126 & 6.8 & - & - & - \\
\hline Prednisone use & & & & & & \\
\hline$>10 \mathrm{mg}$ per day & 296 & 40 & 13.5 & 2.16 & $1.48-3.15$ & $<0.001$ \\
\hline$\leqslant 10 \mathrm{mg}$ per day & 295 & 29 & 9.8 & 1.54 & $1.01-2.35$ & 0.047 \\
\hline 0 & 1,338 & 83 & 6.2 & - & - & - \\
\hline Azathioprine use & & & & & & \\
\hline Yes & 17 & 5 & 29.4 & 4.82 & $1.97-11.75$ & 0.001 \\
\hline No & 1,907 & 147 & 7.7 & - & - & - \\
\hline Physiologic & & & & & & \\
\hline$\%$ Predicted FVC & & & & & & \\
\hline$\leqslant 50$ & 99 & 14 & 14.1 & 4.45 & $2.14-9.44$ & $<0.001$ \\
\hline $51-65$ & 726 & 75 & 10.3 & 3.02 & $1.69-5.33$ & $<0.001$ \\
\hline $66-79$ & 677 & 48 & 7.1 & 2.18 & $1.28-4.18$ & 0.005 \\
\hline$\geqslant 80$ & 412 & 14 & 3.4 & - & - & - \\
\hline 24-Week change in & edicted FVC & & & & & \\
\hline$\leqslant-10$ & 166 & 39 & 23.5 & 7.06 & $4.21-11.84$ & $<0.001$ \\
\hline-5 to -9.9 & 373 & 45 & 12.1 & 3.43 & $2.07-5.66$ & $<0.001$ \\
\hline 0 to -4.9 & 678 & 34 & 5 & 1.37 & $0.81-2.33$ & 0.237 \\
\hline$>0$ & 638 & 23 & 3.6 & - & - & - \\
\hline \% Predicted DLco & & & & & & \\
\hline$\leqslant 35$ & 397 & 50 & 12.6 & 2.68 & $1.75-4.12$ & $<0.001$ \\
\hline $36-45$ & 716 & 61 & 8.5 & 1.84 & $1.22-2.78$ & 0.004 \\
\hline$>45$ & 772 & 36 & 4.7 & - & - & - \\
\hline 24-Week change in & edicted DLco & & & & & \\
\hline$\leqslant-15$ & 103 & 18 & 17.5 & 4.61 & $2.53-8.38$ & $<0.001$ \\
\hline-14.9 to -10 & 124 & 15 & 12.1 & 2.86 & $1.52-5.39$ & 0.001 \\
\hline-9.9 to 0 & 938 & 62 & 6.6 & 1.56 & $0.99-2.44$ & 0.056 \\
\hline$>0$ & 612 & 27 & 4.4 & - & - & - \\
\hline Dyspnea and HRQL & & & & & & \\
\hline UCSD SOBQ & & & & & & \\
\hline$>80$ & 97 & 14 & 14.4 & 3.37 & $1.74-6.51$ & $<0.001$ \\
\hline $61-80$ & 249 & 24 & 9.6 & 1.89 & $1.07-3.33$ & 0.029 \\
\hline $41-60$ & 433 & 41 & 9.5 & 1.99 & $1.20-3.30$ & 0.007 \\
\hline $21-40$ & 576 & 46 & 8 & 1.62 & $0.99-2.65$ & 0.057 \\
\hline$\leqslant 20$ & 491 & 24 & 4.9 & - & - & - \\
\hline 24-Week change in & SOBQ & & & & & \\
\hline$>10$ & 490 & 71 & 14.5 & 2.73 & $1.96-3.82$ & $<0.001$ \\
\hline
\end{tabular}


TABLE 2. (CONTINUED)

\begin{tabular}{|c|c|c|c|c|c|c|}
\hline Covariates & Subject Visits $(n)$ & Deaths $(n)$ & Deaths (\%) & $\mathrm{HR}$ & $95 \% \mathrm{Cl}$ & $P$ Value \\
\hline$\leqslant 10$ & 1,255 & 68 & 5.4 & - & - & - \\
\hline \multicolumn{7}{|c|}{ SGRQ (summary) } \\
\hline$\geqslant 60$ & 334 & 39 & 11.7 & 2.33 & $1.38-3.93$ & 0.002 \\
\hline $46-59$ & 488 & 40 & 8.2 & 1.56 & $0.93-2.63$ & 0.093 \\
\hline $31-45$ & 527 & 43 & 8.2 & 1.60 & $0.95-2.67$ & 0.075 \\
\hline$<30$ & 413 & 22 & 5.3 & - & - & - \\
\hline \multicolumn{7}{|c|}{ 24-Week change in SGRQ (summary) } \\
\hline$>20$ & 81 & 25 & 30.9 & 5.92 & $3.74-9.37$ & $<0.001$ \\
\hline $11-20$ & 209 & 32 & 15.3 & 2.80 & $1.84-4.25$ & $<0.001$ \\
\hline$\leqslant 10$ & 1,242 & 71 & 5.7 & - & - & - \\
\hline
\end{tabular}

Definition of abbreviations: $\mathrm{Cl}=$ confidence interval; $\mathrm{DL}_{\mathrm{co}}=$ carbon monoxide diffusing capacity; $\mathrm{HR}=$ hazard ratio; $\mathrm{HRCT}=$ high-resolution computed tomography; $\mathrm{HRQL}=$ health-related quality of life; SGRQ = St. George's Respiratory Questionnaire; UCSD SOBQ = University of California San Diego Shortness of Breath Questionnaire.

\section{DISCUSSION}

The clinical course of patients with mild to moderate IPF is characterized by physiologic deterioration (as measured by FVC, DL $\mathrm{D}_{\mathrm{co}}$, and alveolar-arterial oxygen gradient); worsening severity of dyspnea; and frequent hospitalizations for respiratory disorders (3). Hospitalization for a respiratory condition is a particularly ominous event, with up to half of the IPF-related deaths occurring after such an event (3). In addition, although most patients experience an insidious decline in lung function that ultimately proves fatal, considerable intersubject and intrasubject variability may be observed (3). As a result, formulating an accurate prognosis for an individual patient with IPF represents a distinct clinical challenge. Two clinical prediction models have been developed for patients with $\operatorname{IPF}(4,5)$. To date, however, use of these prediction models and corresponding risk scoring systems has been confined to clinical research, largely based on the inclusion of factors that are not widely accessible in the clinical setting or for which the measurement characteristics preclude widespread clinical use.

In the present study, we identified significant predictors of mortality among a well-defined cohort of patients with IPF and developed a simplified scoring system that may be easily used in clinical practice to assess the 1-year risk of mortality for an individual patient. Development of the scoring system was based on data from two of the largest clinical trials to date in patients with IPF; the study population included more than 1,000 patients from the United States and Europe with a wide range of demographic, clinical, and physiologic characteristics. Additionally, although all patients had mild to moderate functional impairment at baseline, many progressed during the period of observation. Consequently, our scoring system should be generalizable to the population of patients typically treated in respiratory clinical practice. We note that because our objective was to use all available data to develop a robust risk scoring system that is sensitive to the potential importance of relatively small differences in variable values, we chose not to split our sample for purposes of validation, and we were unable to validate the risk scoring system using data from a different source. Thus, whether the scoring system would perform comparably in other populations of patients with IPF is currently unknown, and validation using data from other large populations of patients with IPF are therefore needed.

We included only four predictors in our scoring system, each of which can be readily and reliably ascertained in the typical clinical setting. These predictors included age, history of respiratory hospitalization within the previous 24 weeks, percent predicted FVC, and 24-week change in percent predicted FVC. Importantly, we found that a decline in percent predicted FVC as small as 5\% at 6 months was associated with a more than twofold increase in the risk of death over the subsequent 12 months. This finding is particularly noteworthy because it highlights the prognostic significance of changes in FVC that were previously regarded as within the range of test variability and thus evidence of clinically stable disease. Only one other study to date has reported a similar finding regarding the predictive value of categorical changes in FVC less than $10 \%$. In a study that included 84 patients with

TABLE 3. MULTIVARIATE ANALYSES OF PREDICTORS OF
ALL-CAUSE MORTALITY AMONG PATIENTS WITH IDIOPATHIC PULMONARY FIBROSIS

\begin{tabular}{|c|c|c|c|c|c|c|}
\hline & \multicolumn{6}{|c|}{ HR for Death } \\
\hline & \multicolumn{3}{|c|}{ Comprehensive Model* } & \multicolumn{2}{|c|}{ Clinical Model ${ }^{\dagger}$} & \multirow[b]{2}{*}{$P$ Value } \\
\hline & $\mathrm{HR}$ & $95 \% \mathrm{Cl}$ & $P$ Value & $\mathrm{HR}$ & $95 \% \mathrm{Cl}$ & \\
\hline \multicolumn{7}{|l|}{ Age } \\
\hline$\geqslant 70$ & 2.19 & $1.22-3.95$ & 0.009 & 2.21 & $1.35-3.62$ & 0.002 \\
\hline $60-69$ & 1.64 & $0.91-2.94$ & 0.10 & 1.49 & $0.90-2.46$ & 0.120 \\
\hline$<60$ & 1.00 & - & - & 1.00 & - & - \\
\hline \multicolumn{7}{|c|}{ History of respiratory hospitalization } \\
\hline Yes & 2.82 & $1.61-4.97$ & $<0.001$ & 4.11 & $2.57-6.58$ & $<0.001$ \\
\hline \multicolumn{7}{|l|}{$\%$ Predicted FVC } \\
\hline$\leqslant 50$ & 3.90 & $1.49-10.19$ & 0.006 & 5.79 & $2.55-13.15$ & $<0.001$ \\
\hline $51-65$ & 2.35 & $1.18-4.78$ & 0.016 & 3.54 & $1.95-6.44$ & $<0.001$ \\
\hline $66-79$ & 1.46 & $0.73-2.92$ & 0.291 & 2.20 & $1.19-4.09$ & 0.012 \\
\hline$\geqslant 80$ & 1.00 & - & - & 1.00 & - & - \\
\hline \multicolumn{7}{|c|}{ 24-Week change in $\%$ predicted FVC } \\
\hline$\leqslant-10$ & 3.65 & $2.03-6.57$ & $<0.001$ & 7.99 & $5.26-12.14$ & $<0.001$ \\
\hline-5 to -9.9 & 1.95 & $1.24-3.09$ & 0.004 & 2.60 & $1.75-3.85$ & $<0.001$ \\
\hline$>-5$ & 1.00 & - & - & 1.00 & - & - \\
\hline \multicolumn{7}{|l|}{$\%$ Predicted DLco } \\
\hline$\leqslant 35$ & 1.74 & $1.01-2.99$ & 0.046 & & & \\
\hline $36-45$ & 1.29 & $0.78-2.13$ & 0.319 & & & \\
\hline$>45$ & 1.00 & - & - & & & \\
\hline \multicolumn{7}{|c|}{ 24-Week change in $\%$ predicted DLco } \\
\hline$\leqslant-15$ & 2.41 & $1.19-4.87$ & 0.015 & & & \\
\hline-14.9 to -10 & 1.61 & $0.79-3.28$ & 0.190 & & & \\
\hline-9.9 to 0 & 1.29 & $0.78-2.13$ & 0.317 & & & \\
\hline$>0$ & 1.00 & - & - & & & \\
\hline \multicolumn{7}{|c|}{ 24-Week change in HRQL (SGRQ) } \\
\hline$>20$ & 3.63 & $2.08-6.34$ & $<0.001$ & & & \\
\hline $11-20$ & 1.59 & $0.98-2.58$ & 0.058 & & & \\
\hline$\leqslant 10$ & 1.00 & - & - & & & \\
\hline
\end{tabular}

Definition of abbreviations: $\mathrm{Cl}=$ confidence interval; $\mathrm{DLco}=$ carbon monoxide diffusing capacity; HRQL = health-related quality of life; HR = hazard ratio; SGRQ = St. George's Respiratory Questionnaire.

* $\mathrm{n}$ (patient visits) $=1,444, \mathrm{n}$ (deaths) $=110, \mathrm{C}$ statistic $(95 \% \mathrm{Cl}), 0.77$ (0.72-0.81).

${ }^{\dagger} \mathrm{n}$ (patient visits) $=1,854, \mathrm{n}$ (deaths) $=142, \mathrm{C}$ statistic $(95 \% \mathrm{Cl}), 0.75$ $(0.71-0.79)$. 
TABLE 4. MORTALITY RISK SCORING SYSTEM FOR PATIENTS WITH IDIOPATHIC PULMONARY FIBROSIS

\begin{tabular}{|c|c|c|c|}
\hline \multicolumn{2}{|c|}{$\begin{array}{l}\text { (1) Sum individual scores corresponding to level } \\
\text { of each risk factor for a given patient }\end{array}$} & \multicolumn{2}{|c|}{$\begin{array}{l}\text { (2) Find expected } 1 \text {-year probability of death } \\
\text { corresponding to total risk score }\end{array}$} \\
\hline Risk Factors & Score & Total Risk Score & Expected 1-Year Risk of Death \\
\hline \multicolumn{4}{|l|}{ Age } \\
\hline$\geqslant 70$ & 8 & & \\
\hline $60-69$ & 4 & $0-4$ & $<2 \%$ \\
\hline$<60$ & 0 & $8-14$ & $2-5 \%$ \\
\hline History of respiratory hospitalization & & $16-21$ & $5-10 \%$ \\
\hline Yes & 14 & $22-29$ & $10-20 \%$ \\
\hline No & 0 & $30-33$ & $20-30 \%$ \\
\hline$\%$ Predicted FVC & & $34-37$ & $30-40 \%$ \\
\hline$\leqslant 50$ & 18 & $38-40$ & $40-50 \%$ \\
\hline $51-65$ & 13 & $41-43$ & $50-60 \%$ \\
\hline $66-79$ & 8 & $44-45$ & $60-70 \%$ \\
\hline$\geqslant 80$ & 0 & $47-49$ & $70-80 \%$ \\
\hline 24-Week change in $\%$ predicted FVC & & $>50$ & $>80 \%$ \\
\hline$\leqslant-10$ & 21 & & \\
\hline-5 to -9.9 & 10 & & \\
\hline$>-4.9$ & 0 & & \\
\hline
\end{tabular}

* For example: total score for a patient aged 70 years, with no history of respiratory hospitalization, a \% predicted FVC of $51-$ 65 , and a 24 -week change in \% predicted FVC of -5 to -9.9 , is $31(8+0+13+10)$ and predicted 1 -year probability of death, $20-30 \%$.

biopsy-proven IPF, Zappala and coworkers (18) observed a significant increase in the risk of mortality among patients who experienced a $5-10 \%$ decline in percent predicted FVC over 6 months (HR, 2.31 [95\% CI, 1.19-4.50]). Although this study was limited by a relatively small sample size and potential confounding by a range of variables for which we controlled in our study, the magnitude of the observed risk associated with a $5-10 \%$ decline in FVC was strikingly similar to that of the present study (HR, 2.60 [95\% CI, 1.75-3.85]). The discriminative ability of our mortality risk model compares favorably with others, including predictive models for long-term survival after lung transplantation (26). These models, which considered selected pretransplant demographic and clinical characteristics as potential predictors, and separately, post-transplant parameters included in the Lung Allocation System, performed poorly in predicting long-term survival, with $\mathrm{C}$ statistics for the various models all less than 0.60 . $\mathrm{C}$ statistics for several cardiovascular disease models based on data from the Framingham Heart Study range from 0.66-0.79 (23, 27-30).

Consistent with prior research, we also found that baseline percent predicted $\mathrm{DL}_{\mathrm{co}}$ was an important predictor of mortality $(4,5$, $7,8,31,32)$. However, we decided not to include $\mathrm{DL}_{\mathrm{co}}$ in the risk scoring system because it exhibits considerable variability in clinical practice and is not as widely available as the other measures that were included in the abbreviated clinical model. Based on these factors, we concluded that its inclusion would likely limit

TABLE 5. OBSERVED ONE-YEAR RISK OF DEATH AMONG PATIENTS WITH IDIOPATHIC PULMONARY FIBROSIS AND ESTIMATES FROM RISK SCORING SYSTEM

\begin{tabular}{|c|c|c|c|c|}
\hline $\begin{array}{l}\text { Risk Group } \\
\text { (score) }\end{array}$ & $\mathrm{N}$ & $\begin{array}{l}\text { Observed } \\
\text { Risk (\%) }\end{array}$ & $\begin{array}{l}\text { Risk from Scoring } \\
\text { System (\%) }\end{array}$ & Ratio* \\
\hline All patients & 1,854 & 9.7 & 9.9 & 1.02 \\
\hline \multicolumn{5}{|c|}{ Quintiles of patients, by risk score } \\
\hline 1 st $(\leqslant 11)$ & 368 & 3.4 & 2.2 & 0.65 \\
\hline 2nd (12-15) & 359 & 4.4 & 4.1 & 0.93 \\
\hline $3 r d(16-17)$ & 361 & 5.4 & 6 & 1.12 \\
\hline 4 th $(18-24)$ & 384 & 9.3 & 9 & 0.96 \\
\hline 5 th $(\geqslant 25)$ & 382 & 25 & 27.1 & 1.08 \\
\hline
\end{tabular}

* Observed risk versus risk from scoring system. the use of our scoring system among clinicians. Importantly, excluding baseline and longitudinal measures of percent predicted $\mathrm{DL}_{\mathrm{co}}$ (and change in HRQL) had no meaningful impact on model discrimination, suggesting that measures of $\mathrm{DL}_{\mathrm{co}}$ may not be incrementally informative in differentiating between patients with IPF based on their mortality risk (Table 6).

Our findings have several potentially important implications for both clinical practice and clinical trial design. First, although there is considerable variability in prognosis among patients with IPF, our data suggest that an IPF patient's prognosis may be readily and accurately assessed, and such information may be used as a basis for management decisions that are significantly informed by discussions with patients about the relative risks of treatment against the risks of progressive disease. Additionally, our findings may aid in the identification of appropriate candidates for enrollment in clinical trials and facilitate accurate stratification, both of which may contribute to a more efficient and properly "powered" clinical trial.

Some limitations of our study are noteworthy. First, these clinical trials enrolled a group of patients with mild to moderate impairment of pulmonary function at baseline. The study did not include patients who were too ill or considered at high risk for dying during the course of the trial $(2,20)$. We acknowledge in particular the exclusion of patients with severe emphysema, because emerging evidence suggests that comorbid emphysema may have a potentially important impact on survival and

TABLE 6. ALTERNATIVE CLINICAL MODEL SPECIFICATIONS

\begin{tabular}{|c|c|c|}
\hline Model & Independent Variables & C Statistic $(95 \% \mathrm{Cl})$ \\
\hline Clinical model & $\begin{array}{l}\text { Age, respiratory hospitalization, } \\
\text { FVC, } \triangle \text { FVC }\end{array}$ & $0.75(0.71-0.79)$ \\
\hline Model B & $\begin{array}{l}\text { Age, respiratory hospitalization, } \\
\mathrm{DL}_{\mathrm{co},} \Delta \mathrm{DL}_{\mathrm{co}}\end{array}$ & $0.70(0.66-0.75)$ \\
\hline Model C & $\begin{array}{l}\text { Age, respiratory hospitalization, } \\
\text { FVC, } \mathrm{DL}_{\text {co }}\end{array}$ & $0.71(0.66-0.75)$ \\
\hline Model D & Age, FVC, $\mathrm{DL}_{\mathrm{co}}, \Delta \mathrm{FVC}, \Delta \mathrm{DL}_{\mathrm{co}}$ & $0.75(0.71-0.80)$ \\
\hline Model E & Age, FVC, $\mathrm{DL}_{\mathrm{co}}$ & $0.66(0.62-0.70)$ \\
\hline
\end{tabular}

Definition of abbreviations: $\Delta \mathrm{DL}_{\mathrm{co}}=24$-week change in carbon monoxide diffusing capacity; $\triangle \mathrm{FVC}=24$-week change in $\mathrm{FVC} ; \mathrm{Cl}=$ confidence interval; $\mathrm{DL}_{\mathrm{co}}=$ carbon monoxide diffusing capacity. 
longitudinal measures of pulmonary function in patients with IPF. Although the trial populations undoubtedly included some patients with mild to moderate emphysema, further assessment of the prognostic significance of comorbid emphysema was not possible and remains for future research. The generalizability of study results (e.g., the importance of a 5-9\% decline in FVC visà-vis mortality) and the applicability of the risk scoring system to patients excluded from the trial populations are unknown.

Second, although the study database included a broad range of demographic, clinical, and physiologic parameters for a large number of study subjects, potential predictors of mortality that have been reported to be independently significant in several recent small studies were not included in our analysis. Brain natriuretic protein, a noninvasive marker for pulmonary hypertension, was recently shown in one study to be a predictor of mortality in patients with IPF (16). In another recent small study, CT visual scores were found to be a useful predictor of mortality in IPF (14). Additionally, 6-minute walk distance has been reported to be an independent predictor of mortality in patients with IPF on a waiting list for lung transplantation (10). More recently, both baseline 6-minute walk distance and the change in 6-minute walk distance at 12 months were identified as independent predictors of mortality in a small cohort of patients with IPF (17). Whether further research will establish these and possibly other measures as important predictors of mortality in IPF and whether the addition of these predictors to our model would significantly enhance its predictive accuracy is unknown.

Third, although using categorical variables for continuous measures is typically less desirable (vs. considering continuous measures and corresponding higher-order effects), we did so to aid in the interpretation and use of study results. Fourth, hospitalizations were designated as respiratory in nature based on assessments by principal investigators, and such designations were not formally adjudicated. Finally, although our analyses would have ideally been limited to patients randomized to placebo in the clinical trials, we concluded based on the absence of evidence for any treatment effect that the enhanced power of the study to identify independent predictors of mortality justified the inclusion of all randomized patients.

In conclusion, we found that among a large and well-characterized population of patients with IPF several parameters were important independent predictors of mortality, including changes in percent predicted FVC that were previously regarded as evidence of clinically stable disease. We also found that an abbreviated clinical model comprising four predictors that are readily and reliably ascertainable in clinical practice performed well in discriminating between patients with IPF based on their risk of death, and that a risk scoring system based on these characteristics may be used to accurately assess an individual patient's risk of death and facilitate clinical decision making. Additional research using data from other large populations of patients with IPF is needed to validate the applicability and accuracy of our scoring system.

\footnotetext{
Author Disclosure: R.M.d B., served as an investigator in InterMune-sponsored clinical trials; served on a scientific advisory board for InterMune Inc.; and received consultancy fees from InterMune, Boehringer Ingelheim, Actelion, Bayer, and Merck along with lecture fees from InterMune, Actelion, and GlaxoSmithKline. D.W. is a statistical consultant under contract with InterMune Inc. C.A. served as an investigator in InterMune-sponsored clinical trials. W.Z.B. is an employee of InterMune Inc. U.C. served as an investigator in InterMune-sponsored clinical trials and served on a scientific advisory board for InterMune Inc. A.K. is a statistical consultant under contract with InterMune Inc. L.L. served as an investigator in InterMune-sponsored clinical trials. P.W.N. served as an investigator in InterMunesponsored clinical trials and has served on a scientific advisory board for InterMune Inc. G.R. served as an investigator in InterMune-sponsored clinical trials and has served on a scientific advisory board for InterMune Inc. S.A.S. served as an investigator in InterMune-sponsored clinical trials and has served on a scientific advisory board for InterMune Inc. J.S. is an employee of InterMune Inc. M.T. served as an investigator in InterMune-sponsored clinical trials. D.V. served as an investigator in InterMune-sponsored clinical trials. T.E.K. served as an investigator
}

in InterMune-sponsored clinical trials and has served on a scientific advisory board for InterMune Inc.

Acknowledgment: This study was funded by InterMune Inc. The authors are indebted to Kenneth Glasscock for medical writing and editorial assistance and to the participating staff members and patients at all study centers.

\section{References}

1. American Thoracic Society. Idiopathic pulmonary fibrosis: diagnosis and treatment. International consensus statement. American Thoracic Society (ATS) and the European Respiratory Society (ERS). Am J Respir Crit Care Med 2000;161:646-664.

2. King TE Jr., Albera C, Bradford WZ, Costabel U, Hormel P, Lancaster L, Noble PW, Sahn SA, Szwarcberg J, Thomeer M, et al. Effect of interferon gamma-1b on survival in patients with idiopathic pulmonary fibrosis (INSPIRE): a multicentre, randomised, placebo-controlled trial. Lancet 2009;374:222-228.

3. Martinez FJ, Safrin S, Weycker D, Starko KM, Bradford WZ, King TE Jr., Flaherty KR, Schwartz DA, Noble PW, Raghu G, et al. The clinical course of subjects with idiopathic pulmonary fibrosis. Ann Intern Med 2005;142:963-967.

4. King TE Jr., Tooze JA, Schwarz MI, Brown K, Cherniack RM. Predicting survival in idiopathic pulmonary fibrosis: scoring system and survival model. Am J Respir Crit Care Med 2001;164:1171-1181.

5. Wells AU, Desai SR, Rubens MB, Goh NS, Cramer D, Nicholson AG, Colby TV, du Bois RM, Hansell DM. Idiopathic pulmonary fibrosis: a composite physiologic index derived from disease extent observed by computed tomography. Am J Respir Crit Care Med 2003;167:962-969.

6. Latsi PI, du Bois RM, Nicholson AG, Colby TV, Bisirtzoglou D, Nikolakopoulou A, Veeraraghavan S, Hansell DM, Wells AU. Fibrotic idiopathic interstitial pneumonia: the prognostic value of longitudinal functional trends. Am J Respir Crit Care Med 2003;168:531-537.

7. Collard HR, King TE, Bartelson BB, Vourlekis JS, Schwarz MI, Brown KK. Changes in clinical and physiologic variables predict survival in idiopathic pulmonary fibrosis. Am J Respir Crit Care Med 2003;168: 538-542.

8. Flaherty KR, Mumford JA, Murray S, Kazerooni EA, Gross BH, Colby TV, Travis WD, Flint A, Toews GB, Lynch JP 3rd, et al. Prognostic implications of physiologic and radiographic changes in idiopathic interstitial pneumonia. Am J Respir Crit Care Med 2003;168:543-548.

9. Flaherty KR, Andrei AC, Murray S, Fraley C, Colby TV, Travis WD, Lama V, Kazerooni EA, Gross BH, Toews GB, et al. Idiopathic pulmonary fibrosis: prognostic value of changes in physiology and sixminute-walk test. Am J Respir Crit Care Med 2006;174:803-809.

10. Lederer DJ, Arcasoy SM, Wilt JS, D'Ovidio F, Sonett JR, Kawut SM. Six-minute-walk distance predicts waiting list survival in idiopathic pulmonary fibrosis. Am J Respir Crit Care Med 2006;174:659-664.

11. Lettieri CJ, Nathan SD, Browning RF, Barnett SD, Ahmad S, Shorr AF. The distance-saturation product predicts mortality in idiopathic pulmonary fibrosis. Respir Med 2006;100:1734-1741.

12. Hamada K, Nagai S, Tanaka S, Handa T, Shigematsu M, Nagao T, Mishima M, Kitaichi M, Izumi T. Significance of pulmonary arterial pressure and diffusion capacity of the lung as prognosticators in patients with idiopathic pulmonary fibrosis. Chest 2007;131:650-656.

13. Alakhras M, Decker PA, Nadrous HF, Collazo-Clavell M, Ryu JH. Body mass index and mortality in subjects with idiopathic pulmonary fibrosis. Chest 2007;131:1448-1453.

14. Best AC, Meng J, Lynch AM, Bozic CM, Miller D, Grunwald GK, Lynch DA. Idiopathic pulmonary fibrosis: physiologic tests, quantitative CT indexes, and CT visual scores as predictors of mortality. Radiology 2008;246:935-940.

15. Kinder BW, Brown KK, Schwarz MI, Ix JH, Kervitsky A, King TE Jr., . Baseline BAL neutrophilia predicts early mortality in idiopathic pulmonary fibrosis. Chest 2008;133:226-232.

16. Song JW, Song JK, Kim DS. Echocardiography and brain natriuretic peptide as prognostic indicators in idiopathic pulmonary fibrosis. Respir Med 2009;103:180-186.

17. Caminati A, Bianchi A, Cassandro R, Mirenda MR, Harari S. Walking distance on 6-MWT is a prognostic factor in idiopathic pulmonary fibrosis. Respir Med 2009;103:117-123.

18. Zappala CJ, Latsi PI, Nicholson AG, Colby TV, Cramer D, Renzoni EA, Hansell DM, du Bois RM, Wells AU. Marginal decline in FVC is 
associated with a poor outcome in idiopathic pulmonary fibrosis. Eur Respir J 2009;35:830-836.

19. du Bois RM, Albera C, Bradford WZ, Costabel U, Kartashov A, Noble PW, Raghu G, Szwarcberg J, Thomeer M, Valeyre D. Ascertainment of individual risk of mortality for patients with idiopathic pulmonary fibrosis [abstract]. Am J Respir Crit Care Med 2010;181:A2499.

20. Raghu G, Brown KK, Bradford WZ, Starko K, Noble PW, Schwartz DA, King TE Jr. A placebo-controlled trial of interferon gamma-1b in subjects with idiopathic pulmonary fibrosis. N Engl J Med 2004;350: 125-133.

21. Pencina MJ, D'Agostino RB, D'Agostino RB, Vasan RS. Evaluating the added predictive ability of a new marker: from area under the ROC curve to reclassification and beyond. Stat Med 2008;27:157-172.

22. Allison PD. Survival analysis using the SAS System: a practical guide. Cary, NC: SAS Institute Inc.; 1995. p. 292.

23. Wilson PW, D'Agostino RB, Levy D, Belanger AM, Silbershatz H, Kannel WB. Prediction of coronary heart disease using risk factor categories. Circulation 1998;97:1837-1847.

24. Pocock SJ, McCormack V, Gueyffier F, Boutitie F. Fagard RH, Boissel JP. A score for predicting risk of death from cardiovascular disease in adults with raised blood pressure, based on individual patient data from randomized controlled trials. BMJ 2001;323:75-81.

25. Hippisley-Cox J, Coupland C, Vinogradova Y, Robson J, May M, Brindle P. Derivation and validation of QRISK: a new cardiovascular disease risk score for the UK: prospective open cohort study. BMJ 2007;335:136.

26. Gries CJ, Rue TC, Heagerty PJ, Edelman JD, Mulligan MS, Goss CH. Development of a predictive model for long-term survival after lung transplantation and implications for the lung allocation score. $J$ Heart Lung Transplant 2010;29:731-738.

27. Schnabel RB, Sullivan LM, Levy D, Pencina MJ, Massaro JM, D'Agostino RB Sr, Newton-Cheh C, Yamamoto JF, Magnani JW, Tadros TM, et al. Development of a risk score for atrial fibrillation (Framingham Heart Study): a community-based cohort study. Lancet 2009;373:739-745

28. D'Agostino RB Sr, Vasan RS, Pencina MJ, Wolf PA, Cobain M, Massaro JM, Kannel WB. General cardiovascular risk profile for use in primary care: the Framingham Heart Study. Circulation 2008;117: 743-753.

29. Butler J, Mooyaart EA, Dannemann N, Bamberg F, Shapiro MD, Ferencik M, Brady TJ, Hoffmann U. Relation of the metabolic syndrome to quantity of coronary atherosclerotic plaque. Am J Cardiol 2008;101:1127-1130.

30. Wang TJ, Massaro JM, Levy D, Vasan RS, Wolf PA, D'Agostino RB, Larson MG, Kannel WB, Benjamin EJ. A risk score for predicting stroke or death in individuals with new-onset atrial fibrillation in the community: the Framingham Heart Study. JAMA 2003;290:10491056.

31. Mogulkoc N, Brutsche MH, Bishop PW, Greaves SM, Horrocks AW, Egan JJ. Pulmonary function in idiopathic pulmonary fibrosis and referral for lung transplantation. Am J Respir Crit Care Med 2001;164: 103-108.

32. Lynch DA, Godwin DJ, Safrin S, Starko KM, Hormel P, Brown KK, Raghu G, King TE Jr, Bradford WZ, Schwartz DA, et al. High resolution computed tomography in idiopathic pulmonary fibrosis: diagnosis and prognosis. Am J Respir Crit Care Med 2005;172:488-493. 